\title{
Os imigrantes palestinos na América Latina
}

DENISE FAGUNDES JARDIM

O exílio com riqueza é uma pátria. Uma pátria com pobreza é um exílio.

(Provérbio árabe)

$\int$

NTRE OS IMIGRANTES oriundos de países do Oriente Médio, os palestinos são sui generis. Primeiramente, consistem em um desafio para o pesquisador quantificar e demonstrar a extensão do universo de pesquisa. Trata-se de uma imigração que pode ser nomeada como "particular". Nos diversos momentos em que chegam, não há intermediação de uma política imigratória brasileira, nem registros confiáveis da tramitação de vistos de permanência no Brasil. Em segundo lugar, é sempre difícil confiar que uma autodenominação, produzida em diferentes contextos e com uma história tão peculiar quanto aos jogos identitários, se traduza fielmente em números.

Diante dessas características, reportamo-nos à idéia de que os palestinos abarcam uma imigração "recente". Contudo, ouvindo suas histórias relativas à imigração, percebemos que sua vinda fora intermediada tanto por outros imigrantes, chamados por cartas por parentes, e, portanto, não são uma "leva" tão definida em seus contornos temporais. Mantêm uma continuidade com redes de relações de patrícios de outras procedências árabes e compartilham de muitas experiências, entre elas a ocupação inicial como mascates.

Os palestinos são um terço da população refugiada do mundo (Nabulsi, 2003), grosso modo, podemos datá-los como uma imigração de pós-guerra, relativa à criação do Estado de Israel em 1948. Na história de seus desterros, esse é um dos episódios fundamentais, mas há outros fatos anteriores, como mostra Rashid Khalidi (2003), que remetem a disputa e a perda do controle de seus territórios para Israel e relativos à colonização. A experiência dos imigrantes palestinos no Brasil revela os nexos com outras guerras: Guerra dos Seis Dias em 1967, a Intifada em 1987 e os massacres nas cidades de Sabra e Chatila na década de 1980, uma década marcada por guerras civis. Tais fatos permitem entender um constante "ir e vir" de familiares que ora precipitam a emigração ora têm suas viagens de visita à Palestina limitadas em virtude da periculosidade do retorno à sua terra natal.

\section{Os palestinos na América Latina}

Como uma imigração particular, os palestinos chegam à América do Sul como turistas, para realizar visitas a familiares, ou beneficiados pelo contato com 
outros patrícios ou parentes. Esses contatos os conduzem a caminhos já conhecidos por outros imigrantes de procedência árabe, visto que utilizam os mesmos portos de chegada. Em anos recentes, os meios de chegar ao Brasil e a outros países foram se diversificando, e já há distinções nos percursos entre aqueles que ingressam por portos e aqueles que chegam recentemente através de aeroportos. Essa diferença de meios pode significar, entre os palestinos, a indicação de rotas diferentes ou redirecionar suas possibilidades futuras de percurso no Brasil, ampliando-as para outros países da América Latina: Chile, Panamá, Peru, Honduras, Argentina etc. As possibilidades de comunicação e de meios de empreender as viagens têm ajudado a trilhar novos caminhos.

No sul do Brasil, a geração dos imigrantes que entrevistei se refere à entrada no Brasil em virtude da criação do Estado de Israel e o que o fato significou para os jovens da época em termos de possibilidades de trabalho. A imigração significava encarar alguns caminhos. Um deles era destituído de um Estado-nação e, portanto, por meio do estatuto de refugiado. Entrar na esfera da ajuda humanitária tinha um custo imediato, o de não poder circular entre países por uma livre escolha. De outra parte, os documentos para sair da Palestina ou eram israelenses (o que não dava acesso ao mundo do trabalho nos países árabes) ou, na melhor das hipóteses, jordanianos. Concretamente, o trabalho em países do Oriente Médio se inviabilizava.

Por conta dessas escolhas limitadas, é difícil saber quantos são os imigrantes palestinos. Não temos a precisão da burocracia, mesmo para os casos de regularização de papéis no Brasil. Para exemplificar, por trás da regularização de papéis de um jordaniano no Brasil pode haver uma história de uma evasão de uma família palestina que seguiu para a Jordânia e depois enviou seu filho para a América. Mais adiante, mediante contatos familiares e por casamentos por procuração, a família pode custear a vinda da esposa desse filho, que, por hipótese, pode vir do Kuwait. Entenda-se que isso se deve à conexidade das carreiras de trabalho no Oriente Médio, mas essas imprecisões quantitativas nos aproximam ainda mais da singularidade da experiência recente dos palestinos. Uma experiência que é referida pelos informantes, por especialistas em imigração palestina, como uma diáspora.

Em termos gerais, esse segmento evade de uma terra natal em busca de um novo horizonte de trabalho e de cidadania. Se isso não é exclusivo dos palestinos, a singularidade dessa imigração é a ausência de um Estado-nação, e notese que isso acaba incidindo sobre seu percurso. Potencialmente, se tivessem uma formação necessária, um ofício, para trabalhar no Oriente Médio, essas carreiras se inviabilizavam pela ausência de documentos relativos ao pertencimento a um Estado nacional, o que os impedia de transitar imediatamente no mundo árabe. A falta de qualificação necessária não era beneficiada pela vida em aldeias ou campos de refugiados (que comparam com a vida em uma favela). Tal qualificação ali não seria alcançada. Os campos de refugiados são relatados como um lugar de precariedade, de ausência de assistência e sem possibilidades de escola- 
rização. Havia, portanto, a necessidade de criar alternativas, alternativas gestadas nas famílias e nas relações da aldeia de origem, em uma experiência comum que tem revelado a conexidade dos países árabes e da imigração como um modelo para traçar novos destinos.

Segundo Delval (1992), os palestinos são referidos como uma nova onda de imigrantes do Oriente Médio, distintos das levas anteriores de árabes, porque na sua maioria são muçulmanos. É assim que organiza seus dados. Onde há uma mesquita, há a produção de um registro de procedências, o que o leva a estimar a população palestina em 15\% das demais procedências árabes conforme os registros do Centro Islâmico de São Paulo. Meus informantes reiteravam que $10 \%$ dos imigrantes de outras procedências árabes são palestinos. Note-se que as estimativas nativas quase sempre contrastam "nós” os palestinos e "eles", os libaneses.

As considerações de Raymond Delval sobre a presença muçulmana e árabe englobam o sul do Brasil até a cidade de Lages por meio do mapeamento de mesquitas. De resto, não há mesquitas até aquela data, apenas clubes e associações de imigrantes. De 1992 para cá, a criação de novas mesquitas e de salas de oração situadas em clubes e sociedades beneficentes parece ter aumentado consideravelmente, ou pelo menos chamado mais a atenção de cientistas sociais. Mesmo que suas rotinas de registro de sócios estejam restritas a participantes locais, é um local de referência para antigos e novos imigrantes, lugares de referência para estrangeiros que chegam à busca de um lugar em que se fale o idioma árabe. A grande maioria desses palestinos é muçulmana; dizem meus entrevistados que a religião islâmica não exige uma mesquita e uma proximidade maior com agentes religiosos. Entretanto, também essas feições podem estar mudando de acordo com as exigências dos imigrantes e de seus filhos e diante da intensificação de visitas dos Cherk às localidades e clubes. Por exemplo, o clube árabe no Chuí não é somente um espaço de sociabilidade, é também uma sala de orações e, em anexo, há um terreno cercado destinado ao cemitério muçulmano.

Há tantos problemas em quantificar os palestinos que, a bem da verdade, parecem ser "virtuais", inacessíveis. Todavia, atualmente, seus clubes e associações encerram um esforço incrível por reverter essa invisibilidade e por sublinhar sua importância nas relações locais para os "seus" e para os não-migrantes. Mesmo que tais clubes sejam conjunturalmente "abandonados", também podem receber novos protagonistas (líderes da Autoridade Palestina, religiosos muçulmanos) e novos fluxos de ações coletivas que ajudam a realçar a existência de imigrantes de origem palestina na localidade e no mundo.

Para contornar os problemas da difícil quantificação, os trabalhos de pesquisa mais recentes têm realizado entrevistas e trabalho de campo direto e intensivo com os imigrantes palestinos, escutando suas histórias e identificando os percursos adotados. Meu trabalho de campo foi realizado entre os imigrantes de origem árabe, autodenominados palestinos, que vivem no extremo sul do país, na fronteira entre Uruguai e Brasil. Entre os meses de abril de 1996 e 1997, centrei-me na localidade do Chuí, e nos anos posteriores realizei entrevistas 
com filhos desses imigrantes residentes em outras cidades do sul do Brasil. As observações e as entrevistas eram realizadas em suas lojas, que, por vezes, eram também lugar de residência. Minha percepção neste volume deve ser entendida desse singular ponto de vista, como etnógrafa e observadora das redes de relações que passam pelo sul do Brasil (Jardim, 2001).

O universo de minha pesquisa contou com dez famílias, definidas de acordo com seus critérios, o que significa três ou mais unidades domésticas para uma mesma família. Esse trabalho resultou numa etnografia sobre a recriação de tradições e sobre as negociações de identidades diante de diversos "jogos identitários" que detectei na localidade. Por meio de seus relatos e pelos registros documentados que guardavam de uma história recente, pude compreender a complexidade e o investimento subjetivo na autodenominação como palestinos. Foi ali, pela primeira vez, que percebi esse "ir e vir" constante de familiares e amigos de diversas procedências de países do Oriente Médio.

O trabalho sobre imigrações palestinas no sul do Brasil teve seu prosseguimento. Na pesquisa realizada por Peters (2006), recolhendo material empírico e analisando a experiência dos imigrantes palestinos residentes na grande Porto Alegre, contrastamos muitos aspectos da vida familiar. Em comum, ressalta-se a retomada das tradições produzidas na diáspora por parte dos filhos de imigrantes. Peters (2006) analisa os rituais de casamentos como eventos políticos de celebração da origem e de aproximação com os "locais". Outros autores se referem à imigração palestina para a América Latina. Cecília Baeza (2003) analisa a participação dos jovens palestinos na OLP no Chile, mostrando a atividade política como um dos eixos de mobilização transnacional dos filhos de imigrantes.

Assim, contrariando a "lei hanseniana", há uma pluralidade de situações relativas ao ato de rememorar as origens e nem sempre os filhos querem esquecer os valores culturais que remetem ao passado imigrante (Vitar, 2003). No caso dos palestinos, são os filhos que rememoram e recriam noções relativas à identidade étnica. ${ }^{1}$ Além disso, esses filhos não se definem como sujeitos "de origem", e sim como palestinos.

Quanto aos palestinos e às fronteiras internacionais, Muller (2003) nos fornece um registro atual da presença dos palestinos por meio dos jornais locais nas cidades de fronteira e sua inserção das redes de relações entre nacionais. Seu trabalho de campo na área da ciência da comunicação tem se estendido às fronteiras internacionais entre Brasil e Uruguai, Argentina, Paraguai e Bolívia. Todas as cidades de fronteira registram a presença dos palestinos e sua enorme relevância no comércio local.

Pode-se afirmar que esse apreço por cidades de fronteira não é exclusivo dos palestinos. Olhando para as imigrações de procedência semita anteriores, as regiões de fronteira sempre estiveram relacionadas a um forte apelo para a busca de oportunidades. Poderiam ser caracterizadas como uma fronteira em expansão, em que há oportunidades comerciais e, em certo sentido, está longe das rotinas estatais de fiscalização. Meus entrevistados, por exemplo, se reportam a 
inúmera incursões em cidades de fronteiras, ente elas a construção de Brasília e a própria BR 471 que leva até o Chuí na década de 1970.

Paradoxalmente, na atualidade, as fronteiras internacionais parecem exacerbar a noção de controle e presença do Estado, enquanto as rotinas mais corriqueiras mostram um intenso fluxo de pessoas e bens que evidenciam sua porosidade.

Nesse contexto de fronteiras, que remetem a recentes políticas de segurança nacional, os "árabes" saltam aos olhos como "estrangeiros" em potencial e passam a ser vistos de forma singular. São evidenciados como um "outro", de outra nacionalidade, entre nações. Creio que há um problema de enquadramento ao vê-los por esse prisma. Os imigrantes têm sido postos em outros jogos identitários pelo potencial de "estrangeiro" que ocupam. Alguns árabes e palestinos são de fato estrangeiros no sentido de não ter documentos nacionais (de um dos países), mas muitos deles (em especial os representantes religiosos, aqueles estabelecidos no comércio de fronteira) há muito já partilham da vida local e estão plenamente dotados de documentação e de CPF. Portanto, nos jogos identitários, no terrenos das autodenominações e das atribuições, nomear um "estrangeiro" tem sido um jogo complexo de suspeitas, e a nacionalidade, um idioma por excelência das relações de fronteira.

\section{O que há de singular na imigração palestina?}

Tudo nos leva a aproximar as histórias de imigrações dos palestinos com a de outros já conhecidos na literatura sobre a vinda para o Brasil (Lesser, 1995; Nunes, 1996; Truzzi, 1997). Todavia, esses sujeitos nos revelam outros aspectos pouco tratados nas experiências imigratórias anteriores. Primeiro, como ressaltei, evidencia-se um interesse dos filhos de imigrantes no revival das tradições, seja por uma releitura das relações familiares e dos modelos familiares, seja recuperando alguns rituais (familiares e muçulmanos). Há uma participação política nas atividades propostas pelos clubes locais e a Autoridade Palestina tem um forte apelo para essa geração de filhos de evadidos da palestina. Em segundo lugar, esses imigrantes mantêm vínculos multilocais das relações familiares. Há sempre um familiar em outra cidade latino-americana, no continente europeu ou na América do Norte.

Constantemente, por pressão de debates nacionais, nos detemos demoradamente em revelar a história da inserção dos imigrantes entre os nacionais e locais e perdemos de vista as redes de parentes que participam do planejamento da imigração e que permanecem no lugar de origem. No caso dos palestinos, essa rede familiar é ainda mais ampla e multilocalizada, perpassada por uma experiência migratória comum a distintos sujeitos de uma vasta parentela. Cabe perguntar sobre o significado dessas redes de relações multilocais. Seriam elas conjunturais e relacionadas a uma experiência comum de primeira geração de nascidos no Brasil? Elas tenderiam a esvanecer ao longo do tempo de inserção entre nacionais?

De fato, os palestinos e seus filhos fazem coisas inusitadas para as teorias sobre imigração. Com novas possibilidades de comunicação e de trânsito, a conexi- 


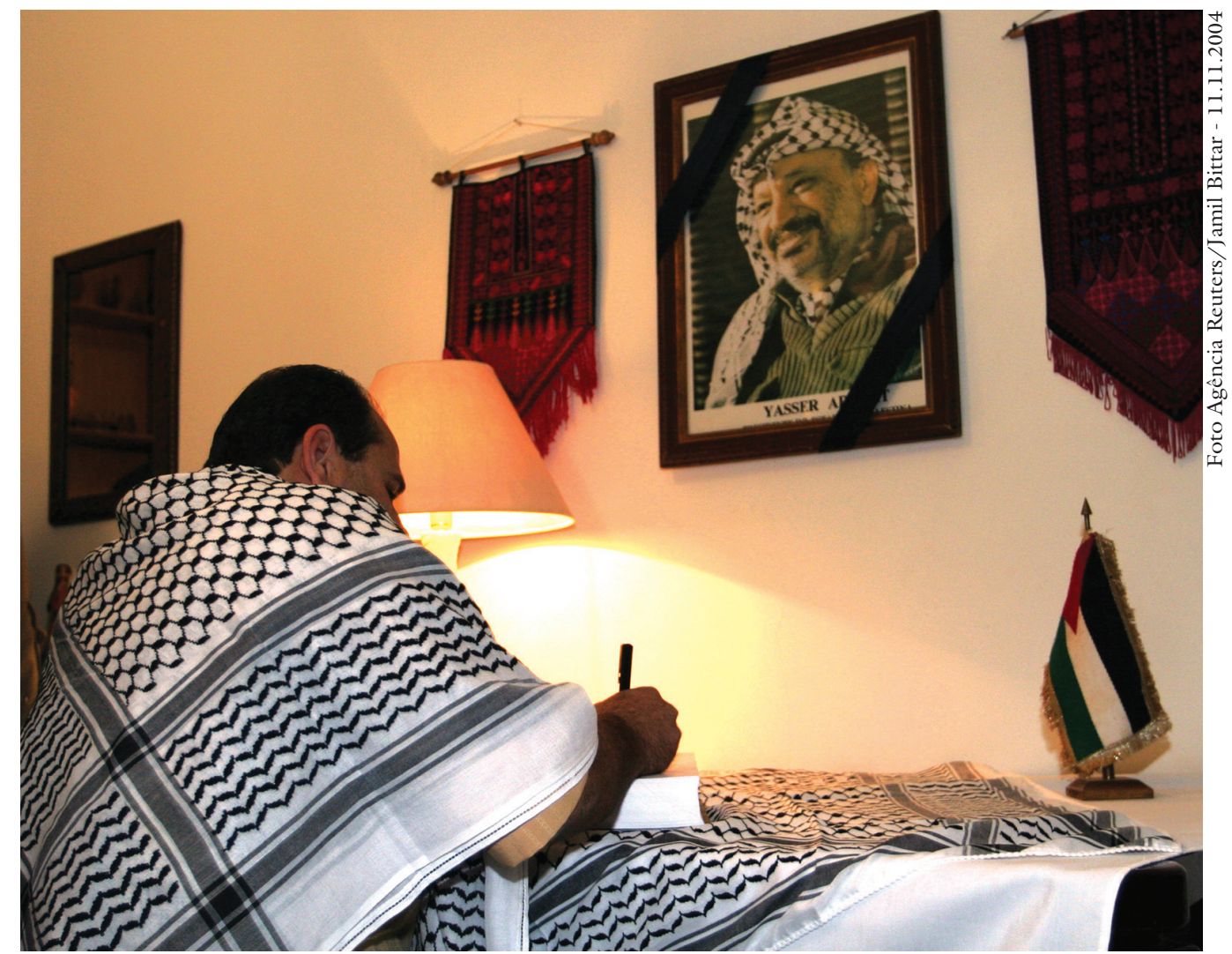

Imigrante assina livro de condolências na embaixada em Brasilia pelo morte de Yasser Arafat.

dade das redes parecem se manter a partir do esforço e do investimento intensivo das mulheres. Nesse sentido, reporto-me ao trabalho de campo que realizei no Chuí. Como mostrei em Jardim (2001), embora o relato da imigração seja uma fala autorizada dos homens, em campo percebi uma intensa troca de informações, fotos e possibilidades de reencontros tecidas pelas mulheres como mães que procuram cônjuges para filhos e filhas ou como tias que participam dessas redes de casamenteiras, planejando novas viagens e deslocamentos familiares.

As viagens que empreendem têm significados diversos: visitam os familiares, retornam aos povoados de origem para reencontrar irmãos ou apresentar seus filhos à parentela ou realizam a obrigação de peregrinar à Meca. $\mathrm{O}$ ideal desses imigrantes parece ser o de reencontrar os parentes e de participar das festas promovidas em distintas localidades. Para os mais velhos, as viagens de retorno são um demarcador na vida do imigrante, pois explicita sua prosperidade para a família de orientação. O retorno com uma mala de presentes é relatado como marcante, depois de anos de imigração. Recordo que esse não é um relato específico dos palestinos, mostra que em muitos aspectos estão "em continuidade" com a experiência de imigração encontrada em outros fluxos de procedência semita.

As rotinas de viagens chamam a atenção de todos, seja porque sempre surge uma esposa trazida de algum país do Oriente Médio, seja porque alguém planeja uma viagem durante muito tempo para si ou para sua família. Ao mesmo 


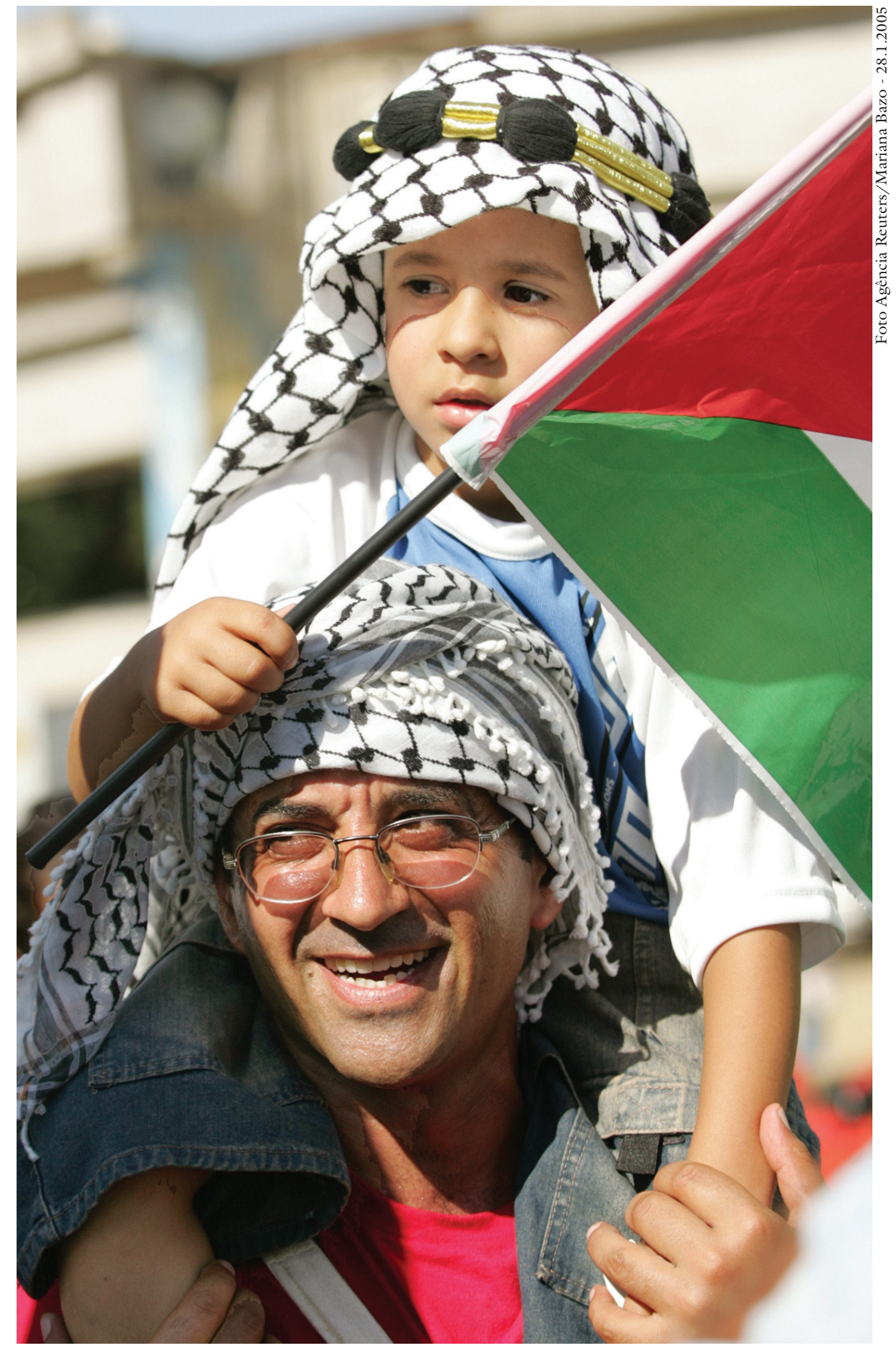

Pai e filho na marcha pró-Palestina durante o Fórum Social Mundial de Porto Alegre (RS). 
tempo que há um revival das tradições, evidenciada na importância e suntuosidade das festas de casamento "ao estilo árabe", as redes de relações "entre" lugares são revitalizadas por meio das viagens. Na experiência atual, todos têm uma história de viagem para contar, sua ou de seus parentes. Portanto, a viagem relatada não se restringe a uma viagem sobre a vinda ao Brasil, mas sobre constantes idas e vindas. Há o relato comum aos jovens filhos de imigrantes escolarizados nos costumes, no idioma, ou relativamente bem familiarizados com práticas testemunhadas na vida familiar travada em outras cidades. As viagens são uma experiência sublinhada como própria dos "árabes" e especial para a vida dos palestinos.

Em trabalhos anteriores, pude explicitar que essas viagens internacionais estão em continuidade com a "diáspora" por eles assim reconhecida. Seja para a busca de um trabalho e horizontes profissionais ou para reorganizar projetos individuais e coletivos, as viagens aparecem como um recurso e uma proposta modelar para resolução de conflitos familiares e definição de destinos na vida adulta. ${ }^{2}$

Do ponto de vista dos "locais", contudo, sobre os palestinos há sempre algo incompreensível a desvendar. Vistos de fora, são sujeitos que viajam muito e parecem viver em uma situação "provisória", um estrangeiro em potencial. Do contrário, vistos pelos "seus", estão em circulação entre lugares, entre ramos da família. As viagens colocam em circulação pessoas e veiculam possibilidades de trabalho, mas também acirram as trocas matrimoniais entre famílias conhecidas de distintas cidades. Dessa maneira, revitalizam os laços de parentesco com imigrantes de outras localidades - o que, em verdade, acaba coincidindo com os parentes do lado paterno -, coincidentemente algo valorizado e que reitera os critérios vigentes na carta constitucional palestina como a definição de direito de cidadania de palestinos na diáspora.

As viagens estreitam vínculos entre os parentes que se encontram na cidade do Chuí (entre Uruguai e Brasil) e aqueles que ficaram lá, como dizem, "no outro mundo", referindo-se ao Oriente Médio. Os imigrantes são explícitos sobre os requisitos necessários para conseguir sua permanência e inserção em outros países. Alguns declinaram de sua permanência no Canadá por não dominarem perfeitamente o francês, só o inglês, o espanhol e o árabe. Outros voltaram de um período prolongado em Nova York, onde eram convidados por seus primos a permanecer. No caso, retornaram para a vida no Chuí envolvidos na vida comercial da família e aproveitando a boa onda do comércio de fronteira (e da diferença cambial ente países), antes do Mercosul. Na época do meu trabalho de campo, em plena vigência do Mercosul, com as fronteiras "abandonadas" pelos compradores, isso era relatado como um erro de cálculo.

Como lembra Sayad (1977), a verdade da imigração é a ruptura. Ao que parece, os palestinos atuam no sentido contrário, no esforço por religar não exatamente à terra de origem, mas a um amplo repertório de referências culturais e de relações familiares. É difícil saber se isso é próprio dos palestinos comum a todo o imigrante de primeira geração. 
Observando os imigrantes palestinos e seus filos, noto que as viagens fazem muitas coisas. Ajudam a revitalizar as redes sociais por meio das quais organizam as permanências em outras cidades e, sobretudo, permitem a redução das diferenças entre visão de mundo entre imigrantes e seus próprios filhos nascidos e criados na sociedade de acolhida. Acabam fabricando um comentário generalizado do que seja a "família árabe", a "sua" família ou o "lado árabe da família". A experiência de deslocamentos é explicada em sua positividade, e não como um desterro. Como me esclarecem, fazendo uma viagem qualquer palestino se reconhece capaz de compreender as inquietações de um outro jovem palestino. Isso significa reconhecer que sua família é composta de muitos primos e cada um em um lugar diferente do planeta.

O provérbio árabe que tomamos como epígrafe externaliza alguns aspectos dessa busca de um "lugar". Para os palestinos, esse lugar não se restringe a traçar uma permanência, e sim em um campo de possibilidades e um futuro promissor. Para tanto, é necessário obter papéis, documentos locais que os situem em um Estado-nação, e acumular um capital cultural exigido para viver em outro país, em outro idioma. O horizonte da "volta" tem sido, sobretudo, uma planificação de reencontros e seus trajetos refletem uma aposta e um risco que deve ser sempre reavaliado.

Tal qual conhecemos em outras imigrações de procedência do Oriente Médio, há uma predominância da imigração de homens solteiros. Contudo, em que pese esse relato centrado no sujeito imigrante, a literatura sobre a imigração árabe tem demonstrado o quanto essa imigração está comprometida com projetos familiares, mesmo que a ruptura seja uma experiência tão marcante. Os imigrantes falam do trabalho autônomo, da negação ao trabalho como empregado, associando tais alternativas a noções de prosperidade e de sucesso da imigração. $\mathrm{Na}$ imigração de palestinos, esse comprometimento familiar se evidencia quando observamos o intenso trânsito de parentes entre as localidade de origem e demais destinos percorridos pela parentela.

O diferencial da imigração palestina talvez não resida unicamente no seu percurso internacional, ou na originalidade de sua história ou das razões de desterro. Creio que eles nos permitem refletir sobre o fenômeno imigratório em sua contemporaneidade.

Os estudos sobre imigrantes palestinos exigem do pesquisador descentramentos teóricos, novos aportes analíticos, porque trazem novas questões à problemática da imigração. Refiro-me às inusitadas práticas de recriações de tradições efetuadas pela primeira geração de filhos de imigrantes e à vitalidade das redes multilocais e transnacionais. É um campo aberto para investigação da conexidade das redes de imigrantes, dando a conhecer um mapa atual da dispersão de sujeitos e famílias de procedência árabe na América latina e, em especial, nos permite conhecer melhor as experiências de diáspora contemporâneas. 
Notas

1 Segundo Marcus L. Hansen, os filhos querem esquecer as origens e os netos querem relembrar.

2 A viagem como um ritual que reorganiza experiências subjetivas e fluxos sociais está presente nos trabalhos de Turner (1974) e Oliveira (1999).

Referências bibliográficas

BAEZA, C. De la conscience diasporique à la mobilisation transnationale: le cas des palestiniens $d u$ Chili. Memoire /Relationes Internationales. Paris: Institut d'Études Politiques de Paris. 2003.

DELVAL, R. Les muçulmans en Amerique Latine et aux Caraibes. In: Recherches \& Documents. Amerique Latines. Paris: L'Harmattan, 1992.

HANSEN, Marcus Lee. The Atlantic Migration, 1607-1860: A history of the continuing settlement of United States. Edited with a foreword by Arthur M. Schlesinger. Cambridge: Harvard University Press, 1945.

JARDIM, D. Palestinos no extremo Sul do Brasil: Identidade étnica e os mecanismos sociais de produção da etnicidade. Chuí/RS, 2001. Tese (Doutorado) - PPGAS, Universidade Federal do Rio Grande do Sul/MN (Impresso \& Cd-Rom) (2000).

KHALIDI, R. La construcción de la identidad. In: La Vanguardia. Dossiê. Los Palestinos. n.8, p.18-21, octubre/diciembre, 2003.

LESSER, J. O judeu é o turco da prestação: etnicidade, assimilação e imagens das elites sobre árabes e judeus no Brasil. Estudos Afroasiáticos, n.27, 1995.

MULLER, K. Mídia e fronteira. Jornais locais em Uruguaiana-Libres e Livramento-Rivera. São Leopoldo, 2003. Tese (Doutorado) - Universidade do Vale dos Sinos.

NABULSI, K. Los refugiados. In: La Vanguardia. Dossiê. Los Palestinos, n.8, p.4954, octubre/diciembre, 2003.

NUNES, H. P. A imigração árabe em Goiás. 1880-1970. São Paulo, 1996. Tese (Doutorado) - Faculdade de Filosofia, Letras e Ciências Humanas, Universidade de São Paulo.

OLIVEIRA, J. P. de. (Org.) A viagem da volta. Etnicidade, política e reelaboração cultural no Nordeste indígena. Rio de Janeiro: Contracapa, 1999.

PETERS, R. Imigrantes palestinos, famílias árabes. Um estudo antropológico sobre a recriação da tradição a partir da festa e rituais de casamento. Porto Alegre, 2006. Tese (Doutorado) - PPGAS, Universidade Federal do Rio Grande do Sul.

SAYAD, A. Les trois “ages” de l'Emigración Algerienne en France. In: Actes de la Recherche, n.17, juin 1977.

TRUZZI, O. Patrícios: sírios e libaneses em São Paulo. São Paulo: Hucitec, 1997.

TURNER, V. Dramas, Fields and Metaphors. Symbolic Action in Human Society. London: Cornell University Press, 1974.

VITAR, B. M. Testimonios orales de los descendientes de sirios-libaneses en San Miguel de Tucumán (Argentina). Trocadero. Revista de Historia Moderna y Contemporánea. 
Consejo Superior de Investigaciones Científicas. Universidad de Cádiz, 2003. (Serie: La Identificación Étnica).

RESUMO - QUANTIFICAR a imigração palestina e conhecer seu percurso na América Latina tem se conformando em um desafio de pesquisa. Neste artigo, problematizo tais dificuldades e trato de aspectos que revelam a experiência palestina em continuidade com outras levas de imigrantes de procedência árabe. Contudo, sugiro a existência de singularidades e novas possibilidades de pesquisa.

PALAVRAS-CHAVE: Palestinos, Diásporas, Minorias nacionais.

ABSTRACT - QUANTIFYING Palestinian immigration and appraising their course in Latin America are topics shaping themselves as a research challenge. In this article, I assess these difficulties and deal with aspects that reveal the Palestinian experience in vis-à-vis continuity with other effluxes of immigrants of Arabian ascent. However, I both suggest that singularities exist and proffer new research possibilities.

KEYWORDS: Palestinians, Diasporas, National minorities.

Denise Fagundes Jardim é antropóloga, professora do Departamento de Antropologia e PPGAS da Universidade Federal do Rio Grande do Sul (UFRG).

@ - denisejardim@yahoo.com.br

Recebido em 9.5.2006 aceito em 11.5.2006. 